\title{
Convergence in the ovipositor system of platygastroid wasps (Hymenoptera)
}

\author{
Elijah J. Talamas', István Mikó², Dylan Johnston-Jordan³ \\ I Systematic Entomology Laboratory, PSI, Agricultural Research Service, U.S. Department of Agriculture, clo \\ National Museum of Natural History, Smithsonian Institution, P.O. Box 37012, MRC-168, Washington, \\ DC 20013-7012 USA 2 Frost Entomological Museum, Pennsylvania University, State College, PA, USA \\ 3 National Museum of Natural History, Smithsonian Institution, P.O. Box 37012, MRC-168, Washington, \\ DC 20013-7012 USA \\ Corresponding author: Elijah J. Talamas (talamas.1@osu.edu) \\ Academic editor: M. Yoder | Received 16 January 2017 | Accepted 26 April 2017 | Published 21 June 2017 \\ http://zoobank.org/41C8781F-8BA7-45FE-872D-A5898DC132DA \\ Citation: Talamas EJ, Mikó I, Johnston-Jordan D (2017) Convergence in the ovipositor system of platygastroid \\ wasps (Hymenoptera). In: Talamas EJ, Buffington ML (Eds) Advances in the Systematics of Platygastroidea. Journal of \\ Hymenoptera Research 56: 263-276. https://doi.org/10.3897/jhr.56.12300
}

\begin{abstract}
It is widely accepted that there are two ovipositor system types in Platygastroidea. The Scelio-type ovipositor system features telescoping conjunctiva between metasomal tergites 6 and 7 and operates via internal changes in hydrostatic pressure alone, whereas muscles are involved in ovipositor extension and retraction in the Ceratobaeus-type. We here provide analyses of ovipositor systems in two platygastrine genera that cannot be classified as either Scelio- or Ceratobaeus-type, but exhibit telescoping conjunctivae and extend the ovipositor system without musculature. These represent unique derivations that are clearly identifiable by the location of the telescoping conjunctiva. In Gastrotrypes Brues, the telescoping conjunctiva occurs between T5 and T6, and in Platygaster tubulosa Brues it occurs between each segment from T3 to T6. If there are convergent derivations of a Scelio-type ovipositor system within Scelionidae (sensu Masner 1976), their identification will require examination of new characters, one of which we provide here, the presence and form of a ring of acanthae on the conjunctiva between T6 and T7.
\end{abstract}

\section{Keywords}

SEM, CLSM, morphology, conjunctiva, parasitoid

Copyright Elijah J.Talamas et al. This is an open access article distributed under the terms of the Creative Commons Attribution License (CC BY 4.0), which permits unrestricted use, distribution, and reproduction in any medium, provided the original author and source are credited. 


\section{Introduction}

The mechanism of ovipositor extension in Platygastroidea is unique among hymenopterans with retracted ovipositors. Outside of Platygastroidea the ovipositor is protracted by the contraction of the 2 nd valvifer-2nd valvula muscles and the anterior pivot of the bulb is often accompanied by posterior rotation of the ovipositor (Figure 1C, Ernst et al. 2013). In Platygastroidea, the mid portion of T9 (tA9: Figures 6, 11 Austin and Field 1997) is elongate and weakly sclerotized, allowing the rest of the ovipositor assembly (first and second valvifers, first, second and third valvulae and proximal (lateral) region of abdominal tergite 9) to protrude telescopically. The biological machinery (e.g. muscles, apodemes) underlying the ovipositor protraction and retraction system of Platygastroidea has not been aligned to that of other Hymenoptera and thus its evolutionary origin has yet to be elucidated. The morphology of platygastroid ovipositor systems has been used for generic diagnoses (Masner 1976, Talamas et al. 2011) and was the sole character source for a morphology-based phylogeny of the superfamily (Austin and Field 1997).

Austin and Field (1997) classified the platygastroid ovipositors into two types: Scelio- and Ceratobaeus-types. In the Ceratobaeus-type, telescopic movement occurs only at the elongate and weakly sclerotized mid portion of T9 and the proximal portion of the ovipositor remains within the apical part of the metasoma, with the exception of Teleasinae (Austin and Field 1997) and Anteris Förster (Talamas et al. 2011). An additional telescoping region can be found between metasomal tergites 6 and 7 in the Scelio-type ovipositor system, causing metasomal tergites 7-9 to be extended with the ovipositor away from the preceding metasomal segments. In this system, the proximal portion of the ovipositor substantially protrudes from $T 7+8$. Although muscles and apodemes on $\mathrm{T} 7+8$ and corresponding sternites are present in the Ceratobaeus-type system, internal changes in hydrostatic pressure likely contribute to ovipositor protraction (Austin 1983, Field and Austin 1994) and thus facilitated the evolution of ovipositor systems that operate via hydrostatic pressure alone. The Scelio-type system was documented in numerous scelionine genera, including Archaeoteleia Masner (Austin and Field 1997, Masner 1976, Masner 1968) and was used to define a putatively monophyletic group, Scelionini sensu lato (Austin and Field 1997).

Austin and Field (1997) provided diagnoses and discussed differences in major platygastroid clades, including Platygastridae s.s., and acknowledged that their observations in this family were preliminary. They listed the reduction and lack of sensory structures on $T 7+8$, and the lack of additional telescoping structures (conjunctiva not extended between T6 and T7) among the diagnostic characters for Platygastridae s.s..

Brues (1922) and Huggert (1980) reported the presence of additional telescoping structures in the ovipositor system of Gastrotrypes and Platygaster tubulosa. Comparison between these ovipositor systems and the telescoping ovipositor system of Scelionidae (sensu Masner 1976) were not mentioned in Austin and Field (1997). We here use scanning electron microscopy and confocal laser scanning microscopy to further document remarkable evolutionary convergence in telescoping ovipositor systems of platygastroid wasps. 


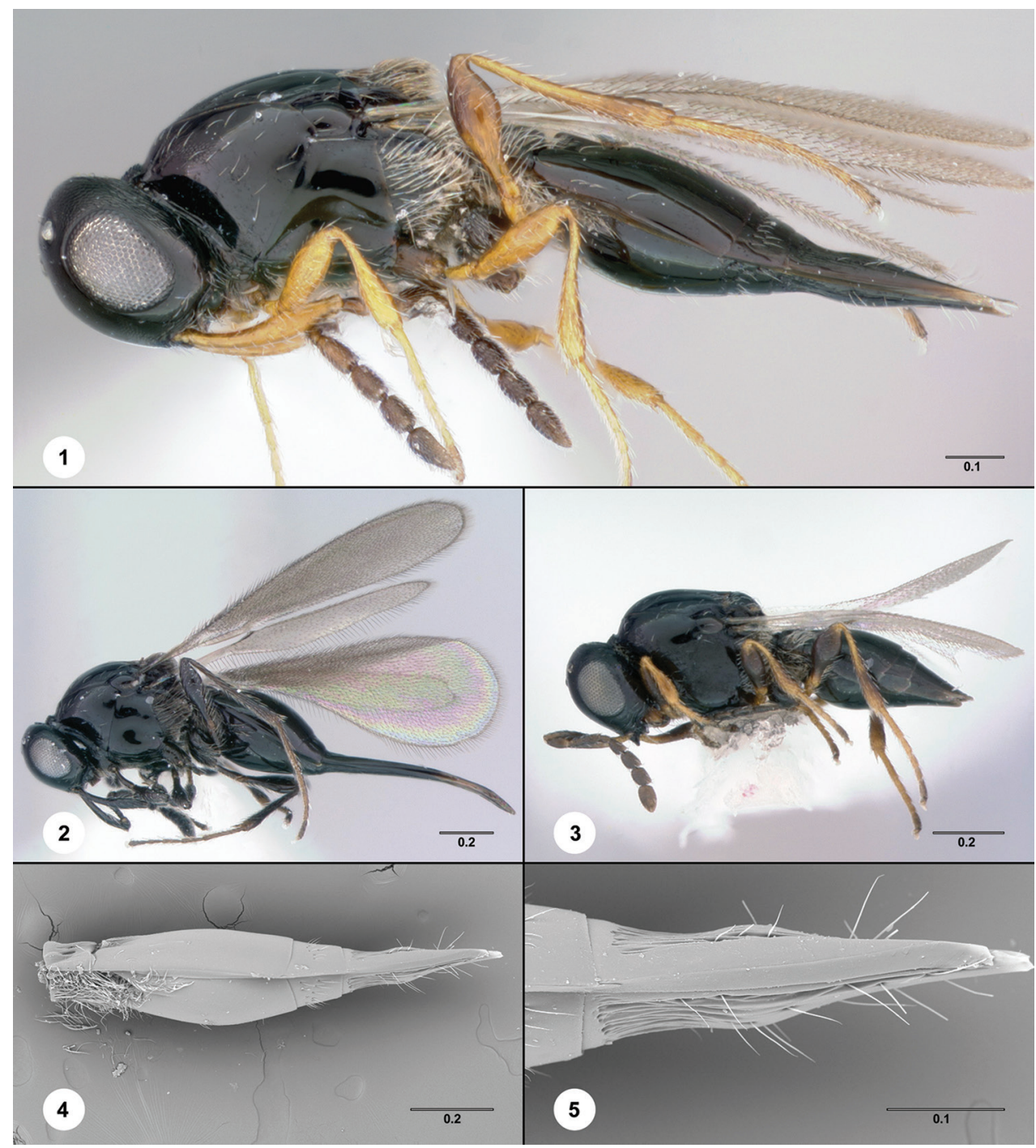

Figures I-5. Metanopedias I female (OSUC 404924), habitus, lateral view 2 female (OSUC 265251), habitus, lateral view 3 female (OSUC 266113), habitus, lateral 4 female (USNMENT00989611_2), metasoma, lateral view 5 female (USNMENT00989611_2), T5, S5, lateral view. Scale bars in millimeters.

Gastrotrypes is cosmopolitan in distribution with seven valid species and numerous species that remain undescribed. Individuals are typically small, often less than $1 \mathrm{~mm}$ in length, and are known to be associated with gall midges that feed in the vascular tissue of freshly cut wood (Brues 1922). Females can be separated from other platygastrine genera by an absence of venation in the fore wing, presence of five externally visible tergites, and by the cylindrical "nozzle" formed by $\mathrm{T} 5+\mathrm{S} 5$ at the apex of the metasoma. Gastrotrypes is very similar to Metanopedias Brues, which 
also has a reduced number of visible tergites ( 4 or 5), but has the apical segments of the metasoma distinctly spatulate (Figures 1-5). Males of both genera have 7 visible tergites and reliable characters to separate male Gastrotrypes from male Metanopedias are not known to us.

Platygaster tubulosa is recognizable by the presence of only two external tergites when the ovipositor system is retracted. Like Gastrotrypes, it is associated with Cecidomyiidae that feed in wood vascular tissue (Brues 1922). Huggert (1980) considered the lumber trade to be the means by which $P$. tubulosa became a "tramp" species, now known from Asia, Europe, Africa and the Americas (Huggert 1980, Notton 2006, Buhl 2011).

\section{Materials and methods}

Dissections for scanning electron microscopy were performed with a minuten probe and forceps and body parts were mounted to a $12 \mathrm{~mm}$ slotted aluminum mounting stub (EMS Cat. \#75220) using a carbon adhesive tab (EMS Cat. \#77825-12) and sputter coated with approximately $70 \mathrm{~nm}$ of gold/palladium using a Cressington ${ }^{\text {बाल }}$ 108 sputter coater. Micrographs were captured using a Hitachi ${ }^{\text {тा }}$ TM3000 Tabletop Microscope at $15 \mathrm{keV}$. Sample preparation for CLSM followed Mikó et al. 2016: specimens were temporarily mounted between two coverslips (\#1.5) in a glycerin droplet. Blu-tack (Bostik, Wauwatosa, WI, USA) was used as spacer because this material does not interact with glycerol. Specimens were examined with an Olympus FV10i desktop CLSM using the 60X objective. Brightfield images were captured with a Z16 Leica ${ }^{\text {Фтм }}$ lens with a JVC KY-F75U digital camera using Cartograph ${ }^{\text {Фтм }}$ software. In some cases, multiple SEM micrographs or photographs were stitched together in Adobe Photoshop CS $4^{\mathrm{DTM}}$ to produce larger images at high resolution and magnification. Full resolution images are archived at the image database at The Ohio State University (specimage.osu.edu).

The numbers prefixed with "USNMENT" or "OSUC " are unique identifiers for the individual specimens (note the blank space after some acronyms). Details on the data associated with these specimens may be accessed at the following link: purl.oclc.org/ NET/hymenoptera/hol, by entering the identifier in the form (e.g. "OSUC 123123")

We apply the terminology from Austin and Field 1997. Morphological terms were matched to concepts in the Hymenoptera Anatomy Ontology (Yoder et al. 2010) using the text analyzer function. A table of morphological terms URI links is provided in Suppl. material 1.

\section{Collections}

CNCI Canadian National Collection of Insects, Ottawa, Canada

OSUC C. A. Triplehorn Collection, The Ohio State University, Columbus, OH, USA 
PSUC Frost Entomological Museum, Pennsylvania State University, State College, PA, USA

USNM National Museum of Natural History, Washington, DC, USA

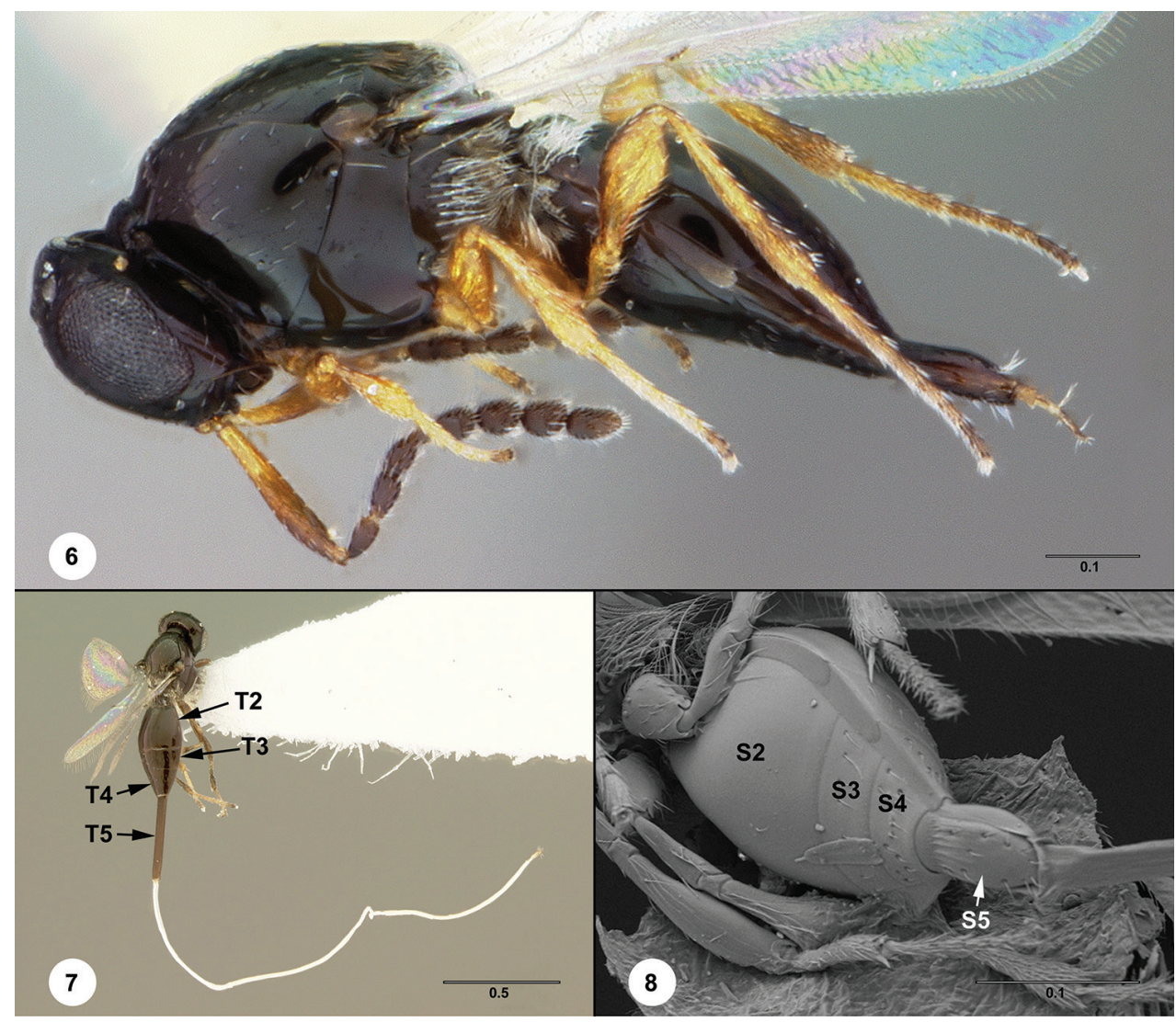

Figures 6-8. Gastrotrypes 6 female (USNMENT01109431), habitus, lateral view 7 female (OSUC 542426), habitus, dorsal view 8 female (USNMENT01109445), metasoma, posteroventral view. Scale bars in millimeters.

\section{Character annotations}

1vf first valvifer (Figure 15)

2vf second valvifer (Figure 15)

3vv third valvula (ovipositor sheaths, Figures 11, 15)

ac acanthae (Figures 11, 14, 30-33)

c cercus (Figures 11, 28-29, 33-34)

cj T5-T6 conjunctiva between T5 and T6 (Figures 17, 20)

il inflection line of telescoping conjunctiva (Figures 11-12, 24) 
lt3-lt5 metasomal laterotergites 3-5 (Figure 15)

T1-T9 metasomal tergites 1-9 (Figures 7, 9-11,13, 15, 18-21, 25-29, 33-35)

trb terebra $\left(1\right.$ st and $2^{\text {nd }}$ valvulae, Figure 15,17$)$

S1-S6 metasoma sternites 1-6 (Figures 8, 15, 19, 21, 25-26, 33-34)
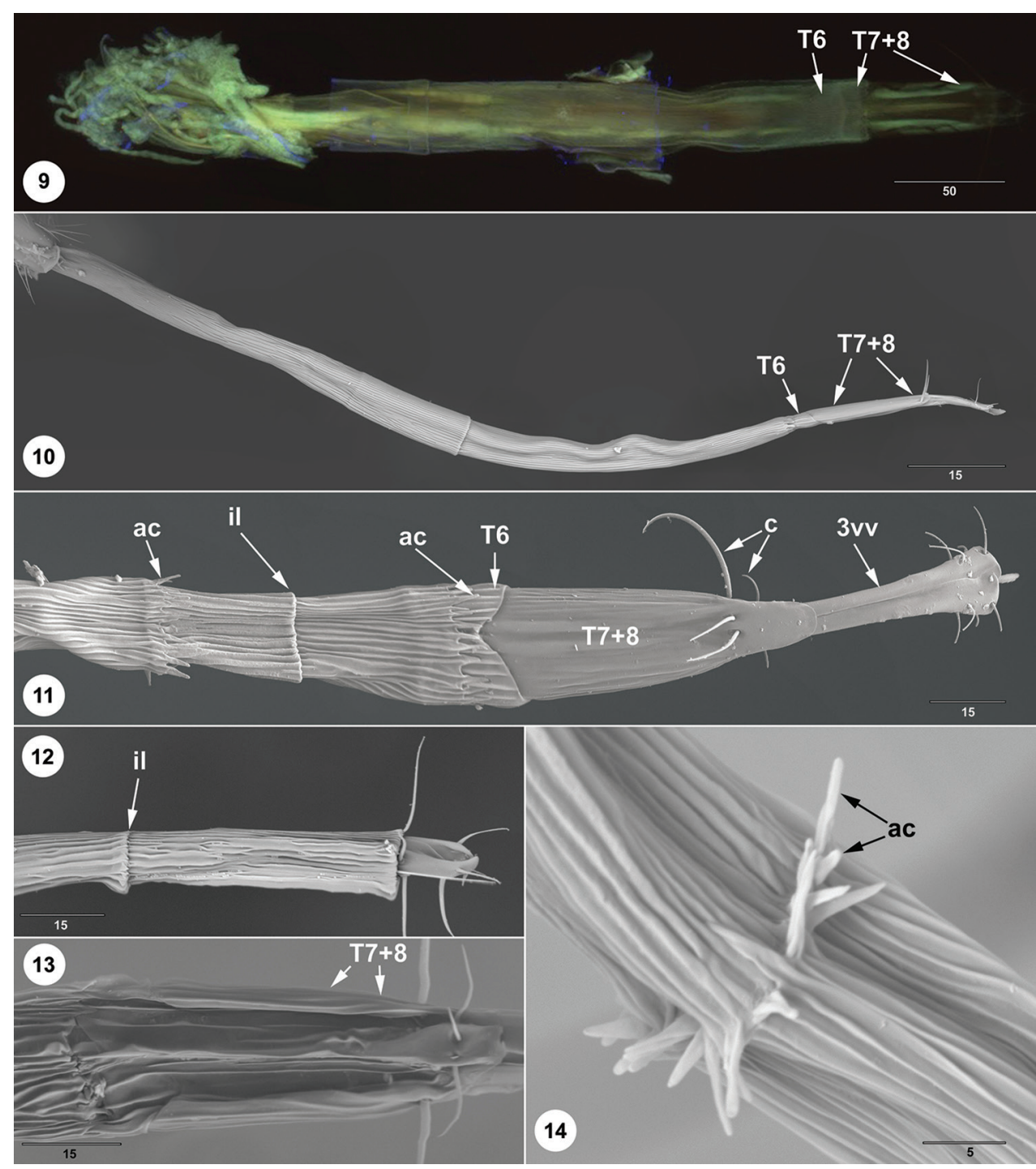

Figures 9-I4. Gastrotrypes 9 female (USNMENT01081081), ovipositor system, ventral??? view $\mathbf{I}$ female (USNMENT01109429), ovipositor system, lateral view I I female (USNMENT01059434), ovipositor system, dorsal view $\mathbf{2}$ female (USNMENT01109445), ovipositor system, dorsolateral view I 3 female (USNMENT01109665), ovipositor system, ventral view 14 conjunctiva, lateral view. Scale bars in microns. 


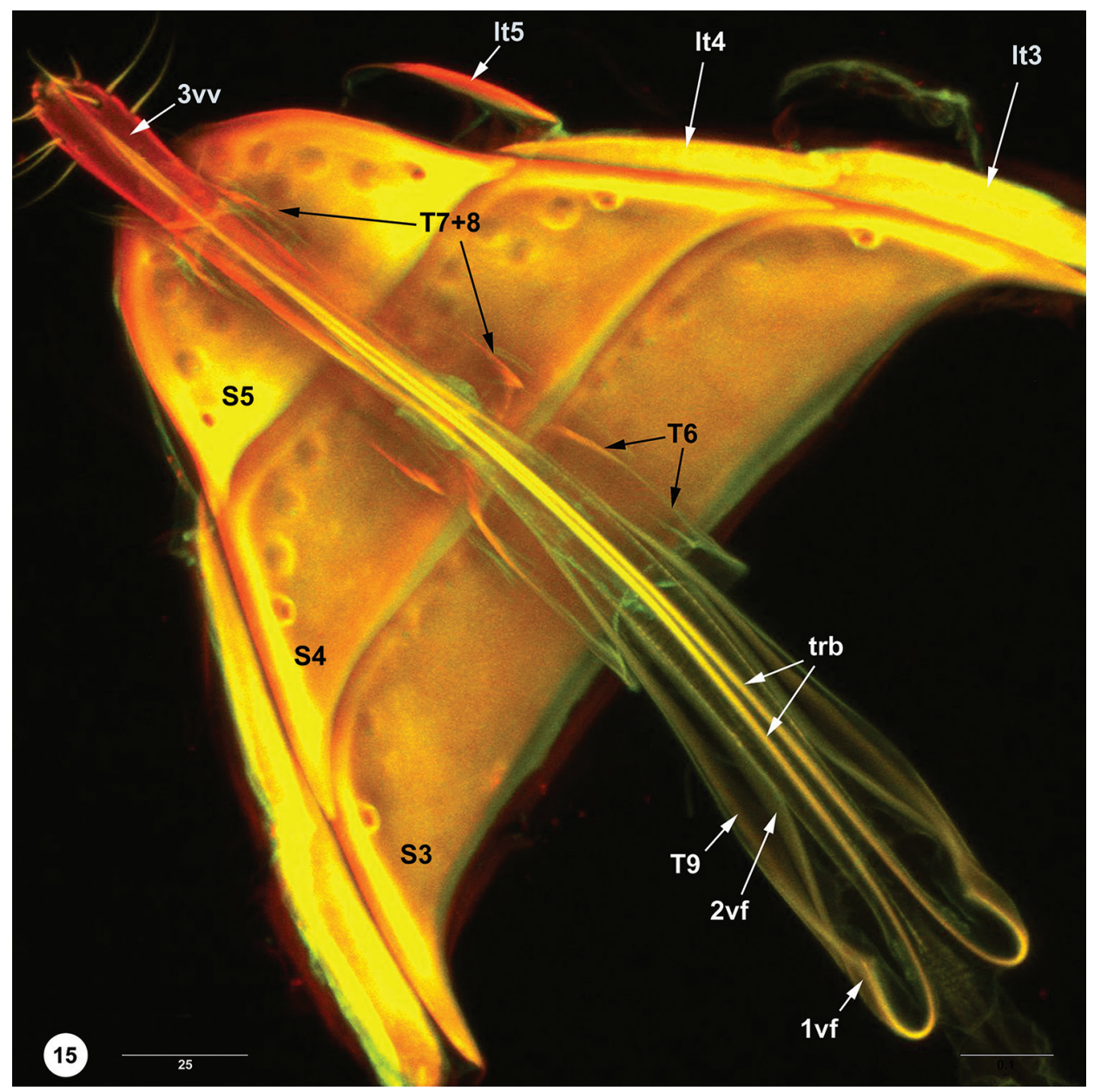

Figure I5. Gastrotrypes sp. female (USNMENT01197222). CLSM volume rendered maximum intensity projection micrograph showing the ovipositor system and distoventral metasomal tergites. Scale bar in microns.

\section{Results}

\section{Gastrotrypes (Figures 6-14)}

The ovipositor system in Gastrotrypes is functionally identical to the Scelio-type in that it possesses elongate, telescoping conjunctiva and distal metasomal segments are protracted with the ovipositor. It differs in that elongation of the conjunctiva occurs between T5 and T6 (Figures 10-11), versus between T6 and T7 in scelionids, and in the longitudinally striate surface sculpture of the conjunctiva (Figures 10-11). T6 is immovably connected to and extruded with $\mathrm{T} 7+8$ during ovipositor extension (Figures 10-11). We interpret the apex of the tergal portion of the ovipositor system to be the fusion of T7 and T8 based on the presence of cerci (Figure 11). 


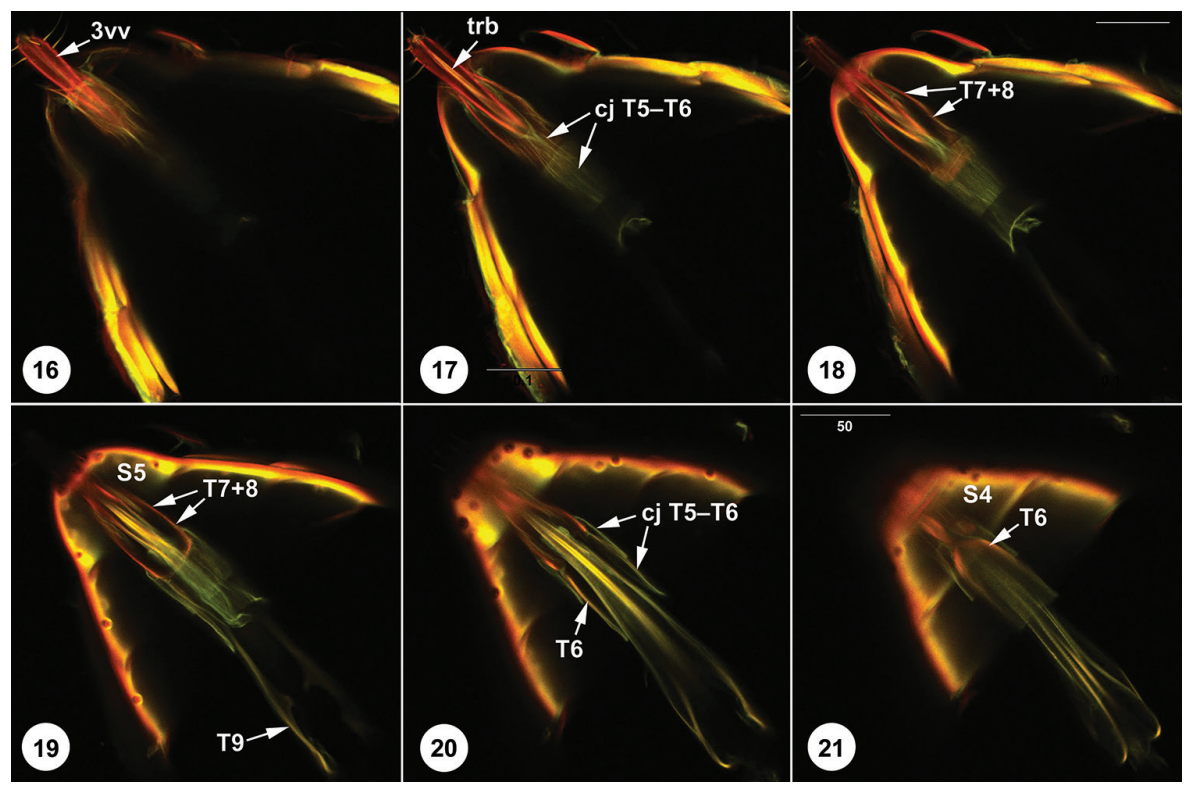

Figures I 6-2 I. Gastrotrypes female (USNMENT01197222). CLSM of metasoma and retracted ovipositor system, ventral view. Scale bar in microns.

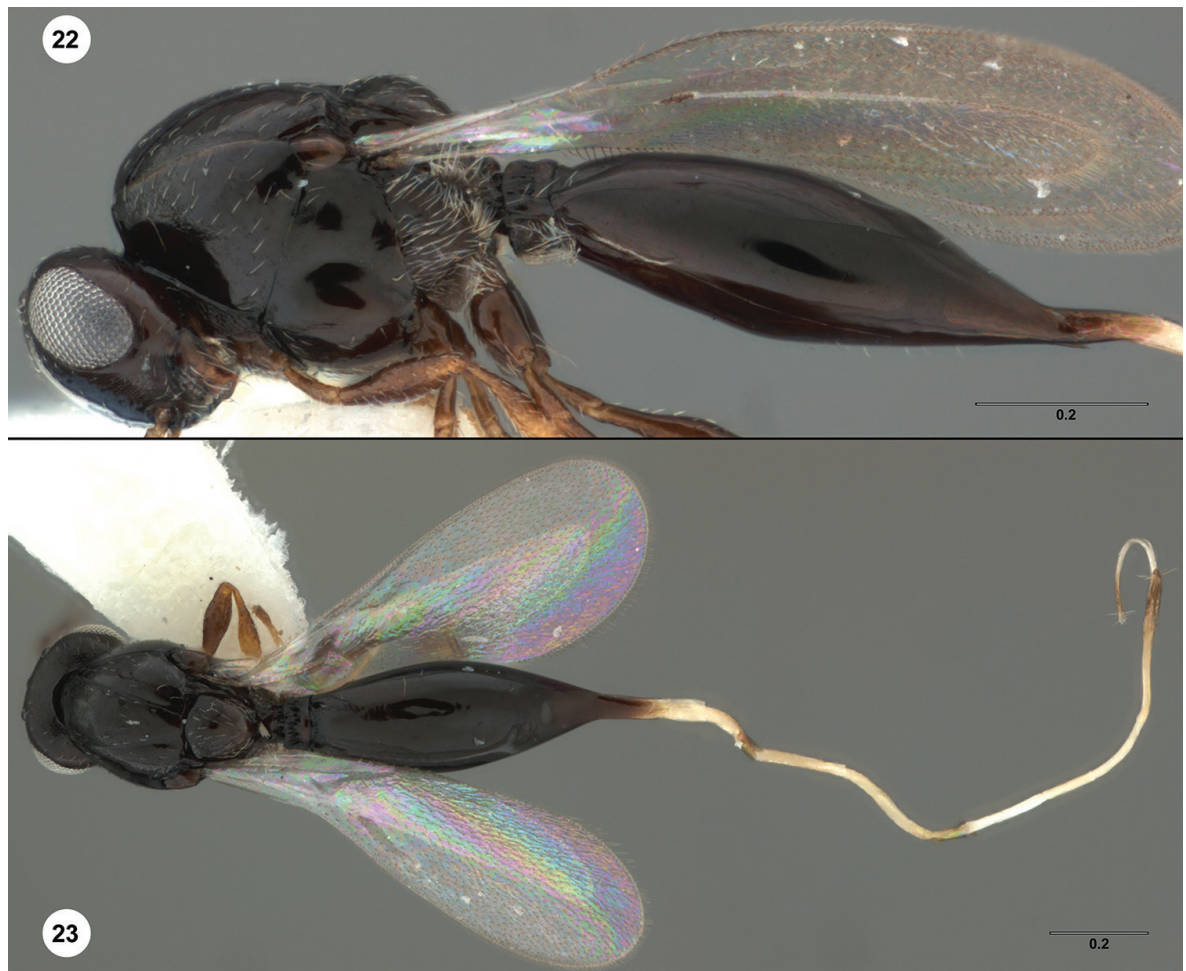

Figures 22-23. Platygaster tubulosa, female (USNMENT01109983) 22 head, mesosoma, metasoma, lateral view $\mathbf{2 3}$ habitus, dorsal view. Scale bars in millimeters. 


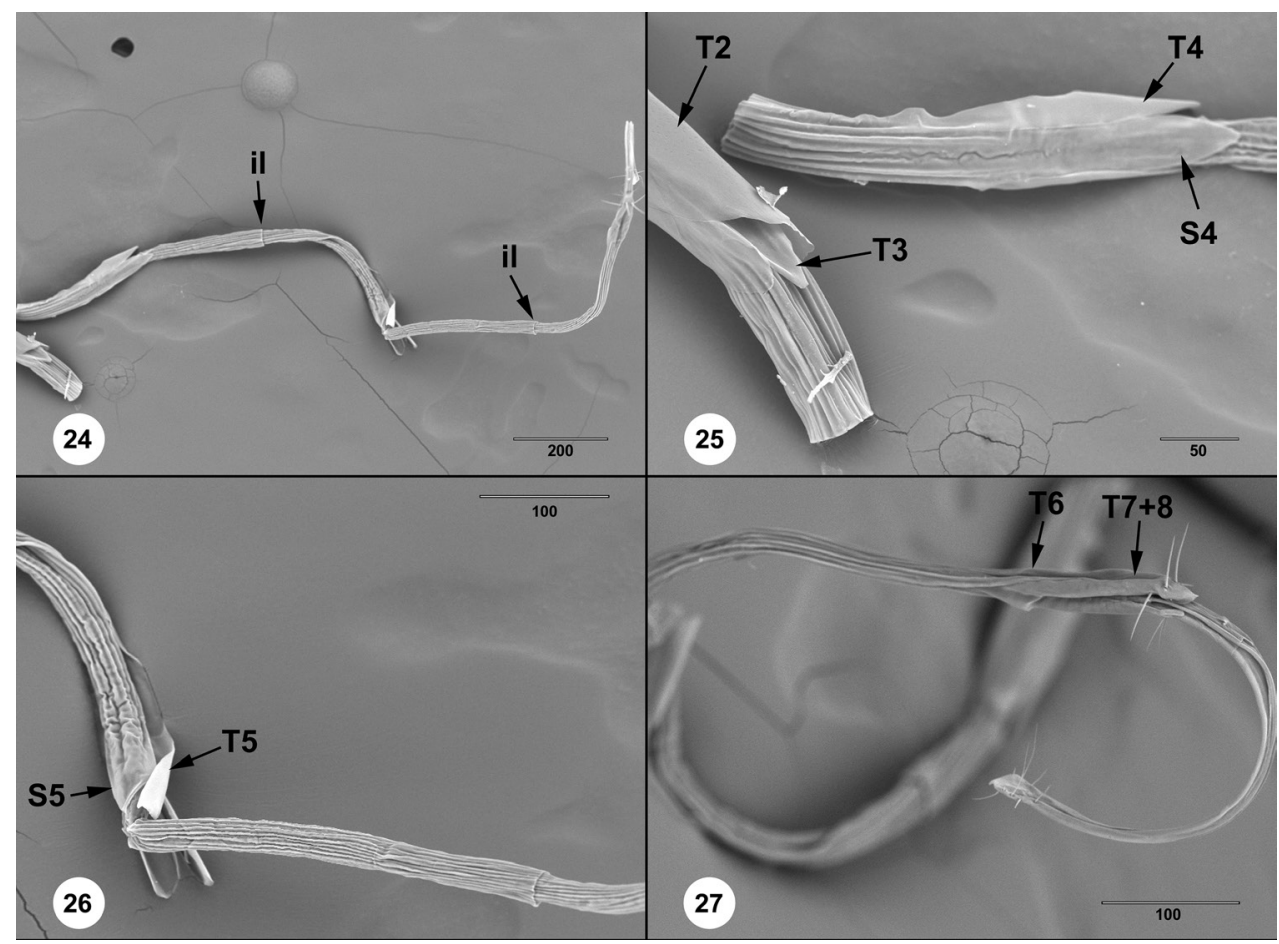

Figures 24-27. Platygaster tubulosa, female (USNMENT01109983) 24 ovipositor system, including metasomal segments 25 T2-T3, dorsolateral view; T4, S4, ventrolateral view 26 T5-S5, ventral view 27 T6-T8, lateral view. Scale bars in microns.

The conjunctiva between T5 and T6 in Gastrotrypes features acanthae where it attaches to the posterior margin of T6 and a second ring of acanthae anterior to its distal inflection site (Figures 11,14). Similar structures exist on the telescoping conjunctiva of at least two scelionine genera, Paridris Kieffer and Calliscelio Ashmead. The location of the acanthae in these scelionines is strikingly analogous with Gastrotrypes, as they are located anterior to the distal inflection site of the conjunctiva between T6 and T7. However, in Paridris and Calliscelio the free ends of the acanthae are directed anteriorly (Figures 23-24) and in Gastrotrypes they are directed posteriorly or outward (Figures $11,14)$. The form of the acanthae varies between the scelionine genera: the apices are rounded in Paridris coorgensis (Sharma) (Figure 23) and pointed in Calliscelio rubriclavus (Ashmead) (Figure 24). We did not find this ring of acanthae in Platygaster tubulosa, Probaryconus Kieffer (Figure 27) or Archaeoteleia (Figure 28). In the latter two cases the ring of acanthae may simply remain inside the portion of the conjunctiva that is not fully extended. We consider this character to have potential for informing relationships between genera of Scelionini sensu lato (Austin and Field 1997) but can draw no further conclusion without examination of more genera.

Similar acanthae types were found on the internal surface of the third valvula in other Hymenoptera (Vilhelmsen 2003, Shah et al. 2013), inside the egg canal (Le Relac 


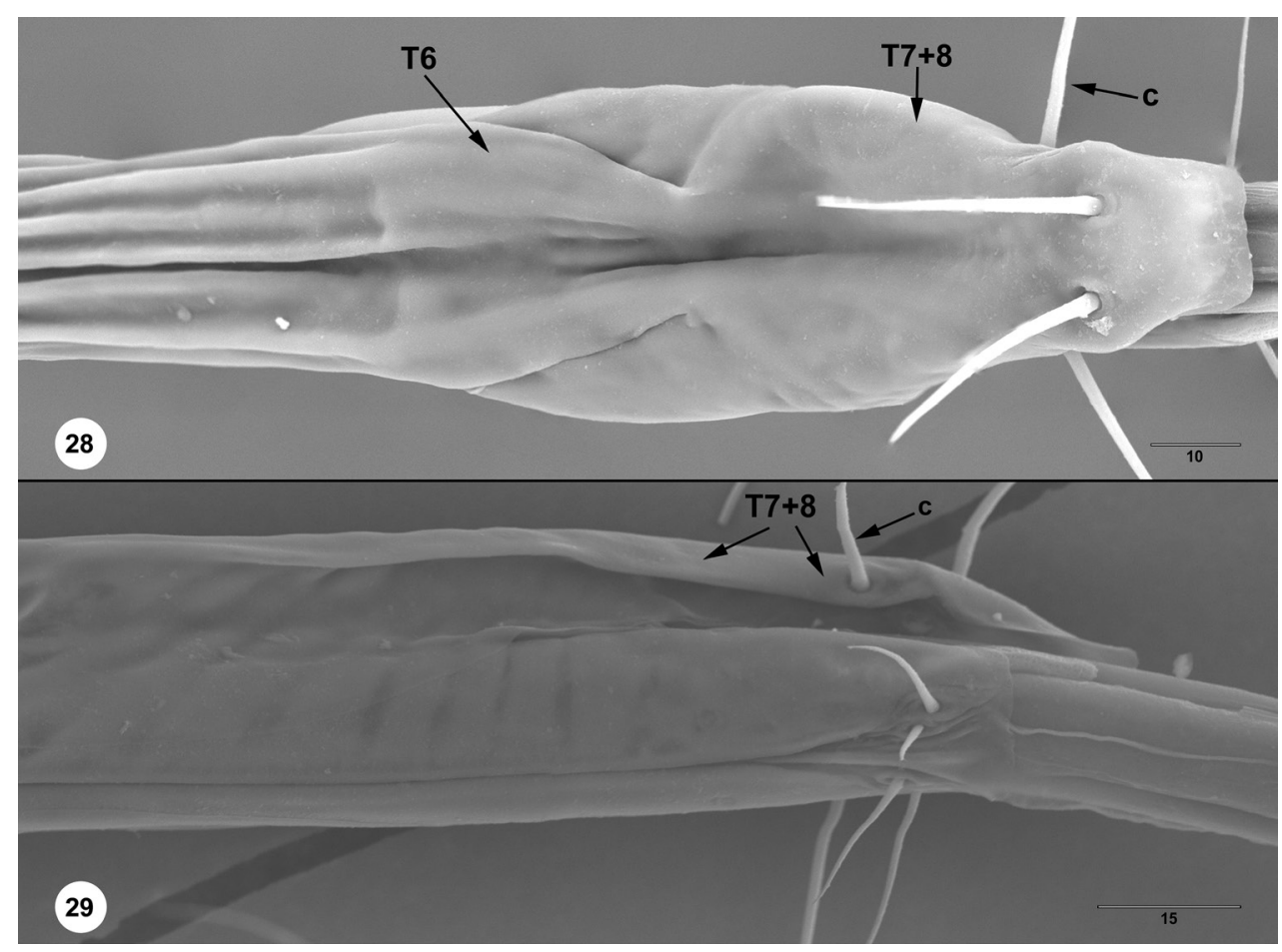

Figures 28-29. Platygaster tubulosa, female (USNMENT01109983) 28 T6-T8, dorsal view 29 T6-T8, ventral view. Scale bars in microns.

et al. 1992) and on the apical metasomal tergites in Ceraphronoidea (Dessart 1999). Based on their size and location relative to the imprints of epidermal cells (scutes, Mikó et al. 2016) these outgrowths are most likely the products of single epidermal cells. Their function is well understood inside the egg canal where they are involved in the motion of the egg (Le Relac et al. 1992) and might have a cleaning function inside the third valvula. It is possible that these structures also function in cleaning the telescopic ovipositor system in Platygastroidea.

\section{Platygaster tubulosa}

The presence of telescoping conjunctiva between each of metasomal segments 3-6 (Figures 17-20) is unique to this species. When the ovipositor system is fully extended, the posterior end of T3 is visible beyond the apex of T2 (T3: Figure 18). T3-T6 and S4-S5 are recognizable as sclerites (T3, T4, T5, T6, S4, S5: Figures 17-21). Ventral to the fusion of T6-T8 is an indeterminate sclerite with a pair of stout setae (Figure 22).

As in Gastrotrypes, the conjunctiva is striate and T6 is immovably attached to T7+8 (Figure 21). Unlike in Gastrotrypes, Paridris or Calliscelio, we found no indication of acanthae on any part of the conjunctiva. 


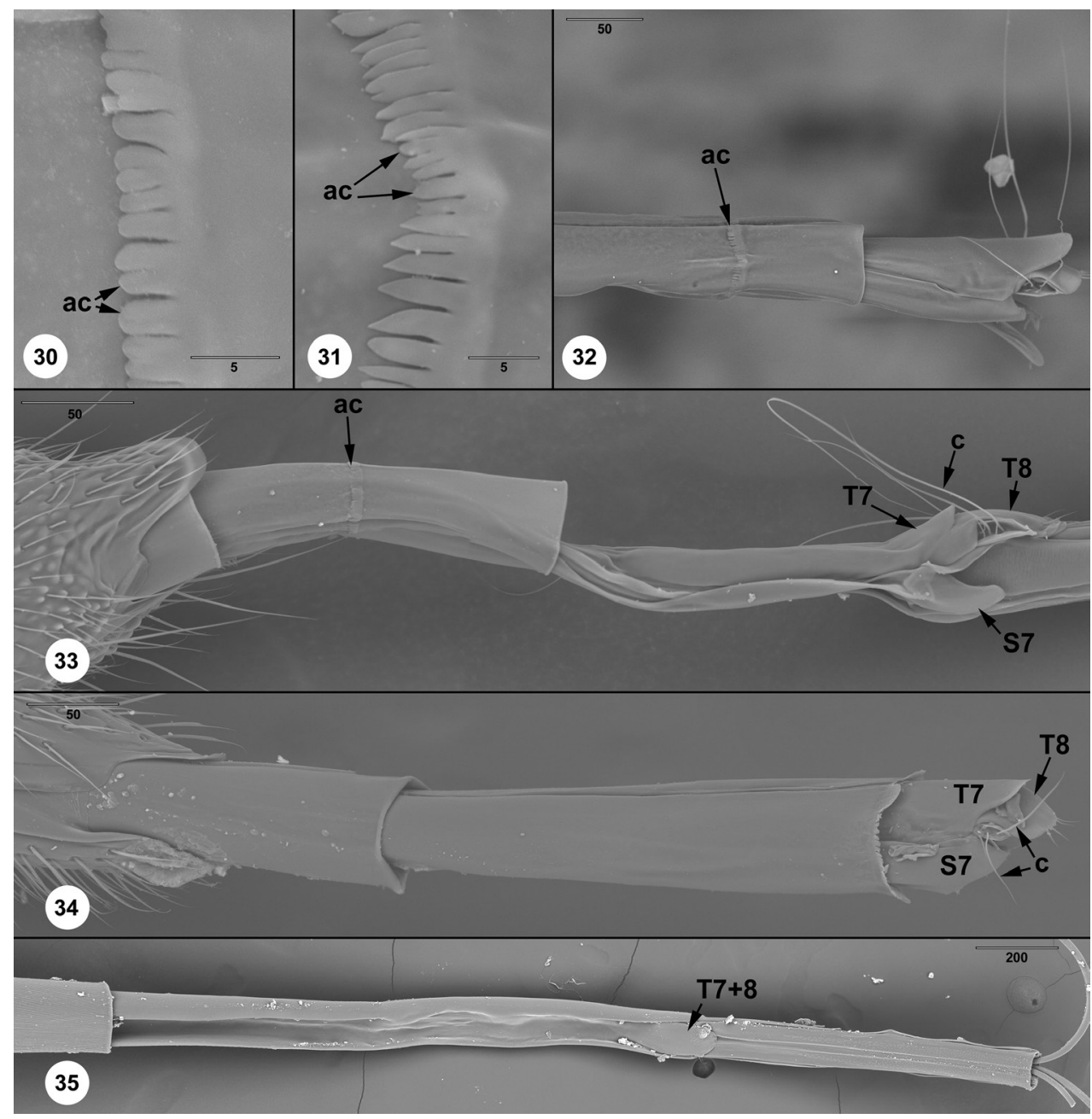

Figures 30-35. 30 Paridris coorgensis, female (USNMENT01223722B), acanthae on conjunctiva, lateral view 3 I Calliscelio rubriclavus, female (USNMENT01109461), acanthae on conjunctiva, lateral view 32 Calliscelio rubriclavus, female (USNMENT01109461), apex of extended ovipositor system, lateral view 33 Paridris coorgensis, female (USNMENT01223722B), T6-T8, lateral view 34 Probaryconus, female (USNMENT01223862), T6-T8, lateral view 35 Archaeoteleia mellea, female (OSUC 203348), T6-T8, lateral view. Scale bars in microns.

\section{Discussion}

We treat the telescoping ovipositor systems in Gastrotrypes and Platygaster tubulosa as independent derivations based on multiple lines of evidence: the plesiomorphic condition for Platygastridae s.s. is a Ceratabaeous-type ovipositor (Murphy et al. 2007); Platygastrinae is phylogenetically distant from scelionids with a Scelio-type ovipositor (Murphy et al. 2007); and elongation of the conjunctiva occurred on different places on the metasoma: between T5 and T6 in Gastrotrypes and between multiple segments 
in $P$. tubulosa. These results suggest a degree of plasticity in the ovipositor systems of Platygastroidea that is consistent with the findings of Murphy et al. (2007), in which phylogenetic analysis retrieved multiple reversals from Scelio- to Ceratobaeus- type ovipositors in Scelionidae, and two derivations of the Scelio-type ovipositor. One derivation of the Scelio-type ovipositor occurred in the main scelionid clade (= Scelionidae sensu Masner (1976) excluding Archaeoteleia and Sparasionini), and the other in Archaeoteleia.

Identification of convergence will ultimately be determined by morphological analysis and the phylogenetic placement of Archaeoteleia relative to the main scelionid clade, a task challenged by what appears to be a significant age difference between these lineages. Archaeoteleia has existed for at least 99 Mya based on a specimen in Burmese amber (Talamas et al. 2017), whereas the oldest reliable fossil of a Scelio-type ovipositor from the main scelionid clade has an age of $-45 \mathrm{Mya}$ (Talamas and Buffington 2015). Morphological evidence that elongation of conjunctiva between T6 and T7 occurred independently in Archaeoteleia and the main scelionid clade exists in two characters, albeit tenuously. Within Scelionidae, the presence of longitudinal striation on the conjunctiva is known only from Archaeoteleia (Austin and Field 1997), and the ring of acanthae at inflection points on the conjunctiva is known from two scelionid genera, but not Archaeoteleia. Examination of the latter character in specimens from a broad range of genera, and from specimens with fully extended ovipositor systems, is needed to determine the degree to which it is informative.

\section{Author contributions}

EJT: project conception, photography, electron microscopy, manuscript preparation, character analysis; IM: confocal laser scanning microscopy, character analysis, manuscript preparation; DJ-J: scanning electron microscopy.

\section{Acknowledgments}

We are grateful to Lubomir Masner (CNCI) for donating specimens of Platygaster tubulosa and Norman Johnson (OSUC) for developing and maintaining the Hymenoptera Online Database and Specimage. This work was made possible by funding from the Systematic Entomology Laboratory and the National Institute of Food and Agriculture-Specialty Crop Research Initiative (USDA-NIFA-SCRI) \#2011-5118130937. The USDA does not endorse any commercial product mentioned in this research. USDA is an equal opportunity provider and employer. 


\section{References}

Austin AD (1983) Morphology and mechanics of the ovipositor of Ceratobaeus Ashmead (Hymenoptera: Scelionidae) and related genera. International Journal of Insect Morphology and Embryology 12: 139-155. https://doi.org/10.1016/0020-7322(83)90006-5

Austin AD, Field SA (1997) The ovipositor system of scelionid and platygastrid wasps (Hymenoptera: Platygastroidea): comparative morphology and phylogenetic implications. Invertebrate Taxonomy 11: 1-87. https://doi.org/10.1071/IT95048

Buhl PN (2011) Species of Platygastrinae and Sceliotrachelinae from rainforest canopies in Tanzania, with keys to the Afrotropical species of Amblyaspis, Inostemma, Leptacis, Platygaster and Synopeas (Hymenoptera, Platygastridae). Tijdschrift voor Entomologie 154: 75-126. https://doi.org/10.1163/22119434-900000309

Brues CT (1922) Some hymenopterous parasites of lignicolous Itonididae. Proceedings of the American Academy of Arts \& Sciences 57: 263--89. https://doi.org/10.2307/20025917

Dessart P (1999). Révision des Dendrocerus du groupe "halidayi" (Hym. Ceraphronoidea Megaspilidae). Belgian Journal of Entomology 1: 169-275.

Ernst A, Mikó I, Deans A (2013) Morphology and function of the ovipositor mechanism in Ceraphronoidea (Hymenoptera, Apocrita). Journal of Hymenoptera Research 33: 25-61. https://doi.org/10.3897/jhr.33.5204

Field SA, Austin AD (1994) Anatomy and mechanics of the telescopic ovipositor system of Scelio Latreille (Hymenoptera: Scelionidae) and related genera. International Journal of Insect Morphology and Embryology 23: 135-158. https://doi.org/10.1016/0020-7322(94)90007-8

Huggert L (1980) Taxonomical studies on some genera and species of Platygastrinae (Hymenoptera: Proctotrupoidea). Entomologica Scandinavica 11: 97-112. https://doi. org/10.1163/187631280X00428

Le Ralec A, Rabasse JM, Wajnberg E (1996) Comparative morphology of the ovipositor of some parasitic Hymenoptera in relation to characteristics of their hosts. The Canadian Entomologist 128: 413-433. https://doi.org/10.4039/Ent128413-3

Masner L (1976) Revisionary notes and keys to world genera of Scelionidae (Hymenoptera: Proctotrupoidea). Memoirs of the Entomological Society of Canada 97: 1-87. https://doi. org/10.4039/entm $10897 \mathrm{fv}$

Mikó I, Trietsch C, Sandall E, Yoder M, Hines H, Deans AR (2016) Malagasy Conostigmus (Hymenoptera: Ceraphronoidea) and the secret of scutes. PeerJ 4:e2682. https://doi. org/10.7717/peerj.2682

Murphy NP, Carey D, Castro L, Dowton M, Austin AD (2007) Phylogeny of the platygastroid wasps (Hymenoptera) based on sequences from the 18S rRNA, 28S rRNA and CO1 genes: implications for classification and the evolution of host relationships. Biological Journal of the Linnean Society 91: 653-669. https://doi.org/10.1111/j.1095-8312.2007.00825.x

Notton DG (2006) Genus-group taxa of Platygastroidea (Hymenoptera: Scelionidae \& Platygastridae) new to Britain. Entomologists Monthly Magazine 142: 189-206.

Shah ZA, Blackwell A, Hubbard S (2012) Ultramorphology of the ovipositor of Venturia canescens (Gravenhorst) and possible mechanisms for oviposition. International Journal of Agriculture \& Biology 14: 908-914. 
Talamas EJ, Masner L, Johnson NF (2011) Revision of the Paridris nephta species group (Hymenoptera, Platygastroidea, Platygastridae). Zookeys 133:49-94. https://doi.org/10.3897/ zookeys.133.1613

Talamas EJ, Buffington ML (2015) Fossil Platygastroidea in the National Museum of Natural History, Smithsonian Institution. Journal of Hymenoptera Research 47: 1-52. https://doi. org/10.3897/JHR.47.5730

Talamas EJ, Johnson NF, Buffington ML, Dong Ren D (2016) Archaeoteleia Masner in the Cretaceous and a new species of Proteroscelio Brues (Hymenoptera, Platygastroidea). In: Talamas EJ, Buffington ML (Eds) Advances in the Systematics of Platygastroidea. Journal of Hymenoptera Research 56: 241-261. https://doi.org/10.3897/jhr.56.10388

Vilhelmsen L (2003) Flexible ovipositor sheaths in parasitoid Hymenoptera (Insecta). Arthropod Structure \& Development 32: 277-287. https://doi.org/10.1016/S1467-8039(03)00045-8 Yoder MJ, Mikó I, Seltmann K, Bertone MA, Deans AR (2010) A gross anatomy ontology for Hymenoptera. PLoS ONE 5(12): e15991. https://doi.org/10.1371/journal.pone.0015991

\section{Supplementary material I}

\section{URI table of HAO morphological terms}

Authors: Elijah J. Talamas1, István Mikó2, Dylan Johnston-Jordan

Data type: Microsoft Excel Spreadsheet (.xlsx)

Explanation note: This table lists the morphological terms used in this publication and their associated concepts in the Hymenoptera Anatomy Ontology.

Copyright notice: This dataset is made available under the Open Database License (http://opendatacommons.org/licenses/odbl/1.0/). The Open Database License $(\mathrm{ODbL})$ is a license agreement intended to allow users to freely share, modify, and use this Dataset while maintaining this same freedom for others, provided that the original source and author(s) are credited. 